
\title{
BResarch Soutere \\ The Process and Effects of Group Sandplay on the Intervention of the Children's Problem Behaviour From the Perspective of Mentalization
}

\section{Qi Hui Zhao}

Children's Hospital of Fudan University https://orcid.org/0000-0001-6586-3315

Kan Chen ( $\square$ chenkan@fudan.edu.cn )

Department of Psychology, Fudan University

\section{Research article}

Keywords: Mentalization, group sandplay, interactions

Posted Date: April 6th, 2021

DOl: https://doi.org/10.21203/rs.3.rs-384441/v1

License: (c) (i) This work is licensed under a Creative Commons Attribution 4.0 International License.

Read Full License 


\title{
The process and effects of group sandplay on the intervention of the children's problem behaviour from the perspective of mentalization
}

\author{
Qi-hui Zhao ${ }^{\mathrm{a}}$, Kan Chen ${ }^{\mathrm{b}}$ \\ a Department of Psychology, Children's Hospital of Fudan University, National Children's Medical Center, \\ Shanghai, China, 201102 \\ b Department of Psychology, Fudan University, Shanghai, China, 200433
}

\begin{abstract}
In this study, we explored the interaction feature among children, and between children and therapists in a group sandplay based on mentalization theory. Six children with behavioural problems are selected and divided into two groups for 10 sandplay therapy sessions lasting for 50 minutes each time. All sandplay videos are coded for behaviour according to grounded theory, and the frequency changes of each behaviour in the early, middle and late stages of the intervention process are compared. The results show that group sandplay based on mentalization can reduce the intervention of the children during sandplay. Empathetic consultation relationship in sandplay based on mentalization theory can improve children's problem behaviors.
\end{abstract}

Keywords: Mentalization, group sandplay, interactions

Corresponding author: Kan Chen, E-mail address: chenkan@fudan.edu.cn 
Mentalization is initiated by the English psychoanalyst Fonagy. It refers to the basic capability acquired by humanin understanding the psychology of themselves and others (Allen, 2003). Specifically, it pertains to the attempt to understand the mental status of oneself and others and the initial ability to understand purposive behaviour and interpersonal interaction accurately through these underlying mental statuses. Mentalization plays the identification, accommodation and expression functions in the process of environment adjustment.

The initiation of mentalization is related to the development and safety of attachment patterns and the mirroring function of caregivers. The safe attachment pattern is prepared for the interactive teaching between the mother and the baby. In a safe attachment relationship, mothers can stimulate their children's cognitive trust. Such trust enables the promotion of the interaction and teaching between the mother and the child (Kim, 2015). The 'mirroring' function of the caregivers promotes the development of children's mentalization. When the caregivers can mark and react appropriately to the babies' emotions, the children will believe that their emotions can be seen and handled. Meanwhile, the children will also be aware that they are different from the caregivers, who can help the children in the transformation from subjective omnipotence to objective reality.

In recent years, the psychotherapy of the children based on mentalization theory has attracted increasing attention from scholars. Assistance to children can be divided into three categories. The first category involves therapy to the mother (Slade et al., 2020; Suchman et al.,2017; Enav et al.,2019). In the second category, family therapy is co-participated by the parents and the children (Muller \& Midgley, 2015; Midgley el al.,2019). The above two 
studies are aimed at improving the mentalization ability of the parents and the interaction skills with the children to achieve the mentalization of the children effectively. Meanwhile, the third category uses game therapy for children (Halfon, Bekar, \& Gürleyen, 2017; Halfon \& Bulut, 2019; Perepletchikova \& Goodman, 2014; Ramires, Schwan, \& Midgley, 2012).

During game therapy, the therapist will help children enhance the reflecting process, which is achieved by providing game chances, feedback emotion and establishing an empathy relationship with the children (Perepletchikova \& Goodman, 2014). Such process is similar to the interaction process between mother and infant. The therapist needs to provide a safe space for the children, where they need not be worried about being harmed. In such space, game, as a symbol, can help the children treat the things that they regard as threats from a backward perspective. This can gradually help them distinguish the boundary between reality and imagination. Moreover, the therapists, as the container, are the mirror of the children. They can help the children in observing their emotions and understanding themselves (Halfon et al., 2017). In such way, children will reflect on themselves better and enhance their understanding of themselves and others. The research shows that therapy models based on mentalization can enhance the mentalization ability and significantly improve children's externalizing problems (Byrne, Murphy, \& Connon, 2020; Halfon \& Bulut, 2019).

Sandplay therapy was founded by Dora Kalff. It features unconscious work, the symbolic analysis principle and the inductive healing mechanism. Similar to game therapy based on mentalization, sandplay is also symbolic. In this approach, children construct their inner world through sand and tools to express their emotions. The therapist provides feedback 
on the interactions in the group sandplay process of the children, thus helping the children express their thoughts and emotions and enhancing their mentalization development.

The current studies are mainly focused on the exploration of the results of game therapy based on mentalization theory, while few are focused on the process. Few potential influencing factors have been initiated. In this study, the influence of the group sandplay based on mentalization theory on the children's behaviours is explored. Moreover, the interaction changes between the children and their companion, the children and the therapist, are analysed in the process.

\section{Methods}

Objects

The research objects are children in kindergarten and first graders in primary school in Shanghai. Six children are selected, who are recommended by the teacher and then screened using the Conners Child Behaviour Scale (for teachers), whose scores are higher than two standard deviations among the four scores according to the norm standard (Fan \& Du, 2004). Six children are classified into two groups according to their ages, with three in each group. The average age of children in the primary school group is 6.7 years old, all of which are boys. The average age of children in the kindergarten group is 4.7 years old, with two boys and one girl. The children are all given consent by their parents to participate in the sandplay. In addition, an informed consent form is signed. This study has passed the ethical review.

Research tools

Conners Child Behaviour Scale (for teachers): A total of 28 items are included in the 
scale, each of which is scored from 0 to 3. Finally, four factors are evaluated: conduct problems, hyperactivity, inattention-passiveness and hyperactivity index. The scale is determined to have good reliability and validity.

Manual for coding the children's behaviour in sandplay: In the previous literature, the main coding dimensions in the children's game process include the relationship with the therapist and the interaction pattern with peers (Karaca, Uzun, \& Metin, 2020; Kennedy-Behr, Rodger, \& Mickan, 2013; Trawick-Smith \& Dziurgot, 2011). The manual for coding the children's behaviour in the group sandplay interactions is formed according to the mentioned coding dimensions and the consideration of the content coding gained by the relevant characteristics of the children's group sandplay.

\section{Table 1}

Manual for coding the children's behaviour in the group sandplay interactions

\begin{tabular}{|c|c|c|}
\hline Interaction & Specific characteristics & Examples \\
\hline Express & Expressing disgust to the & As the therapist reminds the children that the \\
\hline negative & therapist or disaffection to the & time limit is approaching, member D is \\
\hline emotions to the & therapist's behaviour & dissatisfied with the therapist and says, 'You \\
\hline \multirow[t]{2}{*}{ therapist } & & must be a false teacher,. A real teacher would \\
\hline & & not be like this'. \\
\hline Express & Show preference & Member F says to the therapist, 'I am fond of \\
\hline positive & & you'. \\
\hline emotions to the & Invite the therapist to join the & Member D says to the therapist, "please play \\
\hline therapist & play or show curiosity to the & with us, and this one is for you (hold a sanding \\
\hline
\end{tabular}


therapist

Share experiences with the

therapist

Feed or help the therapist

symbolically

Interfere the

peers during

play

'boundary' of others.

Deliberately knock over or

destroy others' sand tools by

hand or using tools.

Change,remove, inverse, bury or

place others' sand tools first

Evaluate others' arrangements of

sanding tools

Advise on the sanding tools

arrangements of others

Request for others to pass the

sanding tools

Attack the tool for the therapist)'.

Member E holds the defected sanding equipment

and says to the therapist, 'This head is taken off.

I dreamt yesterday that my mother was broken'.

Member B makes juice from the plasticine and

says to the therapist, 'Here you are'.

Member F first marks a place for him to play.

Afterwards, he sets a tree in the sand. Then,

member D pulls out the tree and laughs. Member

F shouts out angrily, 'What are you doing now!'.

Member D holds a stick to pull down the

sanding tools that member E has just placed.

Member B buries the sand tools placed by

member A with sand.

Member C says to member A, 'You put it

wrongly. It should be put backwards'.

Member C says to member B, 'You can build a

house'.

Member F says to member D, 'Give me the

spoon!'.

Member B shouts out very angrily about 
peers during

play

Depreciating others

Teasing (prank)

Rob things and push others

Throw sand or sanding tools at

others

Hit or push others

Cooperate with Actively help others find sand

the peers during tools

play

Share with peers and be accepted

Help others settle conflicts

Negotiate with others member A's interference, 'I will kill you'.

When member $\mathrm{D}$ argues with member $\mathrm{F}$,

member F shouts, 'You are a bad boy. You're

not welcomed'.

When the snake's sanding tool is thrown to

member $\mathrm{F}$ by member D, member F screams,

while member D laughs.

When member $\mathrm{F}$ and member $\mathrm{D}$ fight for a

bottle, member F screams and pushes member

D.

When member D is angry, he dumps the sand onto member $\mathrm{E}$ with a shovel.

Member B is very dissatisfied with member A

and pushes him angrily.

As member F cannot find the sand tool she

wants, member D helps her find it.

Member D hands the spoon to member F and

says, 'This is for you to scoop sand'.

Members D and E are quarrelling. Member F

says to them, 'Stop quarrelling. You guys also

say sorry to each other, OK?'

Pointing to a tool, member $\mathrm{F}$ asks member D, 
'Can I borrow this for a while?'.

Play with a certain common

purpose

Cooperate with others in placing

or no opposition in fixing the

sand tools.

Feed or care for others

symbolicallỳ
Member E says, 'Let's make milk together!'.

Member D helps member E in scooping sand

into the bottle.

Member B digs a river, and member A places a

bridge on the river.

Member B says to member C, 'I own a dessert

factory. What juice would you like to drink?'.

Afterwards, member B pretends to prepare juice

for member $\mathrm{C}$ to drink.

Research process

Currently, sandplay therapy has been widely used for children with behavioural problems. In most studies, the duration of the therapy ranges between 10 and 20 sessions (Han, Lee, \& Suh, 2017; Lu, Petersen, Lacroix, \& Rousseau, 2010; Wang et al., 2017). In this study, 10 therapy sessions are selected, each of which lasts for 50 minutes. Children's interaction changes and interaction relations are studied in a short time. The therapist is psychotherapists certified by the National Health Commission, who have received systematic training in sandplay therapy. In addition, the therapist is supervised by a psychoanalyst from the International Association of Analytical Psychology (IAAP) during the therapy.

Three children are examined as a group to observe the interaction changes in the 
sandplay process. The therapy room is independent and quiet. In the room, a standard sand table and a full range of sand tools are equipped.

In the sandplay therapy, sandplay is firstly introduced to the children. Then, they are invited to use sand tools to build a scene as they want. The therapist should try to avoid evaluating and interpreting the children's work, only to help the child feel their emotions and find the reasons of the emotions. After the play, the therapist should take pictures of the sandplay and remove it.

Data statistics are realised through IBM SPSS Statistics 22 software. The therapy is divided into three stages: early, middle and later stages. Sessions 1-3 are the early treatment period. Sessions 4-6 are the middle treatment period. Meanwhile, sessions $7-10$ are the later treatment period. All the videos recorded from the sessions are encoded. A non-parametric test is performed by taking the treatment stage as the independent variable and the frequency of various interactive behaviours during the sandplay as the dependent variable. Moreover, the relevant analysis on the various behaviours of children is carried out.

\section{Results}

Use of sand table as a symbolic tool

In the treatment, the sandplay as a symbolic tool, provides a 'transition space' for children. In sandplays, children can express their experiences symbolically. When symbols are used, plays can help children connect subjective reality with actual reality. The use of transitional space enables the children to distinguish imagination from reality better, as well as the self from others. 
Among children in the primary school group, the boundary of member B is always invaded. Therefore, in the sandplay, he builds a house and arranges numerous explosives, poisons and power grids around the house. He buries explosives to protect the house. Upon doing this, member B says, 'There is a power grid and poison. No one can enter, nor can the dinosaurs'. He shows his fear in this way. The therapist will respond, 'Dinosaurs threaten your little house, and you are scared (mark the emotions of children). You protect the house by the power grids and poison (describe the physical status of the sanding tool) so that others will not harm the small house, and the small house will be safe (connect the children's behaviour and emotions in a symbolic way)'. The child will understand the cause of the behaviour through such a response, and confirm that he is safe. In the later stage of treatment, member B behaves less defensively. In the last few sandplays, he builds a 'dessert factory' in the original site of the 'poisonous gas field', as he wants to make desserts for other peers.

\section{Influence of the emotion feedback in the children's sandplay process on the children's}

\section{behaviours}

The research shows that the methods in which the therapist understands children's feelings, accommodates children's emotions and helps children understand the production of these emotions are the common factors that enable CBT and PDT to be effective (Goodman, Midgley, \& Schneider, 2016).

The therapist helps the children understand their own thoughts and improve their emotions through giving feedback on the children's thoughts and emotions. Both the children in the kindergarten and in the primary school group have difficulty understanding one another's emotions and needs. For example, in the second therapy session of the kindergarten 
group, member $\mathrm{F}$ is planting a tree, while member $\mathrm{D}$ seems interested in knocking down the tree. Member F becomes extremely angry and shouts at member D saying, 'Member D is a troublemaker, and my home will not welcome you. Here, for member D's prank, member F directly shows dissatisfaction. The therapist attempt to mark these emotions in such similar interactions. For the above scenes, the therapist responds as follows: 'Member F feels extremely angry, as member F does not hope to see his tree being pulled down'. After several repetitions, in the later stage of treatment, member F expresses, 'I feel sad, as member D has been bothering me', concerning member D's interference. Upon such time, member D gives feedback and says, 'I was trying to help you'. When they can express their own thoughts and understand each other's thoughts, the cooperation interactions are increased. The average occurrence of the behaviours in the children's interactions are seen in Table 2 .

\section{Table 2}

Average occurrence of behaviours in children's interactions $(\mathrm{M} \pm \mathrm{SD})$

\begin{tabular}{lccc}
\hline & Early stage & Middle stage & Later stage \\
\hline Total interference times & $10.72 \pm 7.87$ & $10.24 \pm 4.38$ & $4.76 \pm 3.36$ \\
Total attack times & $4.05 \pm 3.90$ & $5.82 \pm 3.92$ & $4.59 \pm 3.68$ \\
Cooperation & $2.78 \pm 2.37$ & $6.24 \pm 4.89$ & $4.82 \pm 4.23$ \\
\hline
\end{tabular}

The results of the M rank sum test show that children's interference behaviours are significantly reduced $\left(X^{2}=6.333, p<0.05\right)$. The attack behaviour $\left(X^{2}=3.000, P=0.223\right)$ and cooperative behaviour $\left(\mathrm{X}^{2}=2.818, \mathrm{P}=0.244\right)$ are not significantly different. 
In the therapy, member E shares a dream about the broken mother with the therapist.

After the sharing, he uses a 'monster' without a head to represent the 'broken mother'. In this way, his emotions are given a tangible shape. After that, he says, 'I am not afraid, as I know it is fake' and finds the head for the 'monster'.

In the later stage of the sandplay therapy, the children express more positive emotions to the therapist. For example, they make the cake for the therapist. With the increase of such actions, the cooperation behaviours of the children in the sandplay correspondingly increase. In the last few sandplay sessions of the kindergarten group, all the children are gathered for a 'cake party'.

During the therapy, positive emotions $\left(X^{2}=7.176, p<0.05\right)$ and negative emotions $\left(X^{2}\right.$ $=8.400, \mathrm{p}<0.05)$ expressed by the children to the therapist both increase. As seen in Table 3 , both positive emotions and negative emotions expressed by the children to the therapist are positively related to cooperation behaviour. Positive emotions expressed by the children to the therapist are negatively related to interference behaviours, as seen in Table 4 .

\section{Table 3}

Average times of emotions expressed by the children to the therapist $(\mathrm{M} \pm \mathrm{SD})$

\begin{tabular}{lccc}
\hline & Early stage & Middle stage & Later stage \\
\hline Express positive emotions to the therapist & $0.06 \pm 0.24$ & $0.12 \pm 0.33$ & $0.83 \pm 1.01$ \\
Express negative emotions to the therapist & $0.06 \pm 0.24$ & $0.41 \pm 0.51$ & $0.59 \pm 0.51$ \\
\hline
\end{tabular}

\section{Table 4}

Relevant analysis of the emotion expression of the children to the therapist and the peer interactions 


\begin{tabular}{lll} 
& therapist & therapist \\
\hline Total interference times & $-.286^{*}$ & -0.066 \\
Total attack times & -0.125 & 0.196 \\
Cooperation & $0.291^{*}$ & $0.583^{* *}$ \\
\hline
\end{tabular}

Note. ${ }^{*} \mathrm{p}<0.05,{ }^{* *} \mathrm{P}<0.01$

The changes of children's interactive behaviour and emotional expression to the therapist is shown in the figure below (Fig. 1 and Fig. 2).

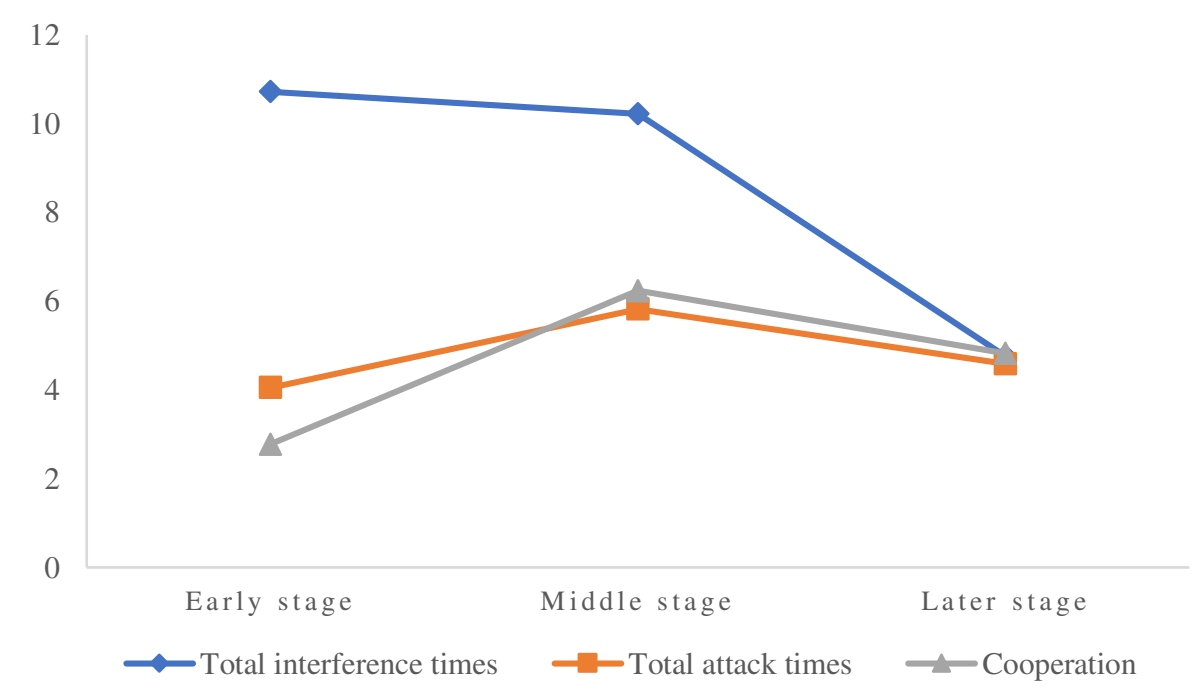

Fig. 1. Average children's children's interactions 


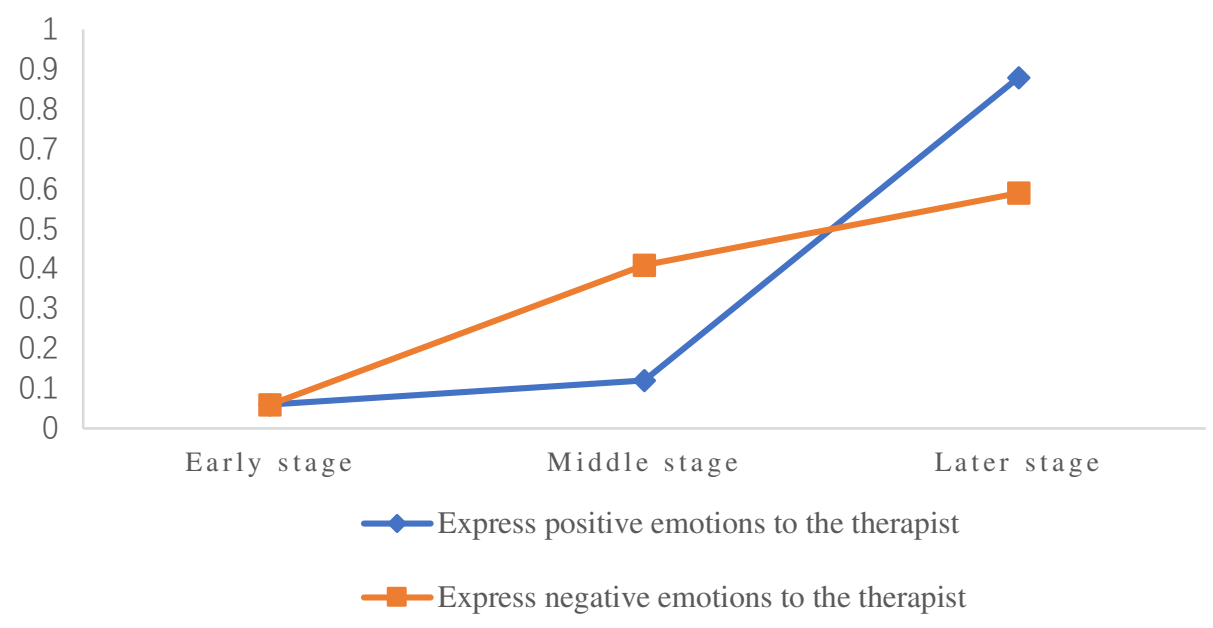

Fig. 2. Average emotion expression of the children to the therapist

Analysis result of the scorer's consistency test

Each video is randomly selected for 5 minutes and is coded by two researchers who have studied the coding manual back-to-back. The scorer's consistency test of the children's interactions are calculated through the Kappa coefficient. The results are shown in Table 5.

\section{Table 5}

Scorer's consistency test results of the children's interactions

\begin{tabular}{lll}
\hline Interactions & Kappa value & Significance level \\
\hline Interference behaviour & 0.874 & 0.000 \\
Attack behaviour & 0.867 & 0.000 \\
Cooperation behaviour & 0.833 & 0.000 \\
Express positive emotions to the therapist & 0.790 & 0.000 \\
Express negative emotions to the therapist & 1 & 0.000 \\
\hline
\end{tabular}

As seen in Table 5, the Kappa consistency coefficients of the two scorers' evaluations on the children's interactions are both above $0.70(\mathrm{p}<0.01)$. As the scorers' consistency is 
high, this study is of good scorer reliability.

\section{Discussion}

During the sandplay therapy process, the therapist helps the children develop mentalization through giving feedback on the children's thoughts and emotions and developing empathy with the sand table, the symbolic tool, as the intermediary.

During the play, the therapist provides a safe environment that is unconditionally accommodated and materials for expressing attack emotions. Moreover, the therapist also sets a certain rule to protect the body and emotional safety. This can help the children better express the attack and other negative emotions (Ritzi, Ray, \& Schumann, 2017).

In the early and middle stages of the therapy, children show a high level of emotional arousal, and their attack behaviour increases. This trend is called the 'arousing spike' (Hayes et al., 2005). During the process, the symptoms deteriorate at first and then improve. Research by Halfon et al. (2016) obtains similar conclusions. Halfon and Bulut (2019) believe that this outcome occurs because at the initial stages, the children express their internal conflict through symbols. The intense emotional arousal leads to the exacerbation of their behaviours in the early stage. Children who are more adherent to therapy show that their emotional control decreases at the beginning and then increases. A stronger adherence leads to a higher level of emotional control achieved after treatment. In such process, the therapist will help the children mark their emotions and help them understand why they possess such emotions. The utilisation of the mental status vocabulary by the therapist (Halfon et al., 2017), and the reflection and handling of the emotions and cognition by the children are beneficial to the improvement of emotions (Hayes et al., 2005). 
In this study, the interference behaviours of the children are reduced, while the cooperation behaviours are not significantly different, which is consistent with the previous study (Han et al., 2017). This outcome is likely because the cooperation behaviours of the children require higher social skills, such as empathy, morality and pro-social behaviour. Moreover, Most of the objects in this study are boys, which may also lead to an insignificant increase in the cooperation behaviour. Previous studies have found that compared with girls, the cooperation behaviour of boys occur later with a shorter duration (Steenbeek, Van der Aalsvoort, \& Van Geert, 2014).

In this study, the children initially express negative emotions to the therapist. This observation is related to the ability of children in object usage. The concept of object usage was initiated by Winnicott. She believes that aggressiveness occupies a transitional position between subjective omnipotence and objective reality. While the object is used, the therapist needs to treat the children in the same manner and nature as before after being attacked. By using the object, children can treat it as a whole other person. When the children establish an attachment relationship with the therapist, the children believe that they can safely express their emotions to the therapist. Then, the therapist can mediate the children's emotions (Halfon, 2017), help them handle more intense emotions and reduce chaos in the sandplay. In conclusion, group sandplay based on mentalization can reduce the interference behaviours of children during sandplay and help the children better handle boundary problems in interpersonal relationships. Moreover, the use of symbols, the empathetic relationship between therapy and children, and the improvement of the reflection process are essential for the development of children's mentalization. 


\section{References}

Allen, J. G. (2003). Mentalizing. Bulletin of the Menninger Clinic, 67(2), 91-112.

Byrne, G., Murphy, S., \& Connon, G. (2020). Mentalization-based treatments with children and families: A systematic review of the literature. Clinical Child Psychology and Psychiatry, 25(4), 1022-1048.

Enav, Y., Erhard-Weiss, D., Kopelman, M., Samson, A. C., Mehta, S., Gross, J. J., \& Hardan, A. Y. (2019). A non randomized mentalization intervention for parents of children with autism. Autism Research, 12, 1077-1086.

Fan, J., \& Du, Y. S. (2004). The norm and reliability of the Conners Teacher Rating Scale in Chinese urban children. Shanghai Archives of Psychiatry, 16(2), 69-71.

Goodman, G., Midgley, N., \& Schneider, C. (2016). Expert clinicians' prototypes of an ideal child treatment in psychodynamic and cognitive-behavioral therapy: Is mentalization seen as a common process factor? Psychotherapy Research, 26(5), 590-601.

Halfon, S. (2017). Play profile constructions: An empirical assessment of children's play in psychodynamic play therapy. Journal of Infant, Child, and Adolescent Psychotherapy, 16(3), 219-233.

Halfon, S., \& Bulut, P. (2019). Mentalization and the growth of symbolic play and affect regulation in psychodynamic therapy for children with behavioral problems. Psychotherapy Research, 29(5), 666-678.

Halfon, S., Bekar, O., \& Gürleyen, B. (2017). An empirical analysis of mental state talk and affect regulation in two single-cases of psychodynamic child therapy. Psychotherapy, 54(2), 207-219. 
Halfon, S., Çavdar, A., Orsucci, F., Schiepek, G. K., Andreassi, S., Giuliani, A., \& De Felice, G. (2016). The non-linear trajectory of change in play profiles of three children in psychodynamic play therapy. Frontiers in Psychology, 7, Article 1494.

Han, Y., Lee, Y., \& Suh, J. H. (2017). Effects of a sandplay therapy program at a childcare center on children with externalizing behavioral problems. Arts in Psychotherapy, 52, 24-31.

Hayes, A. M., Beevers, C. G., Feldman, G. C., Laurenceau, J. P., \& Perlman, C. (2005). Avoidance and processing as predictors of symptom change and positive growth in an integrative therapy for depression. International Journal of Behavioral Medicine, 12(2), 111-122.

Karaca, N. H., Uzun, H., \& Metin, Ş. (2020). The relationship between the motor creativity and peer play behaviors of preschool children and the factors affecting this relationship. Thinking Skills and Creativity, 38, Article 100716.

Kennedy-Behr, A., Rodger, S., \& Mickan, S. (2013). Aggressive interactions during free-play at preschool of children with and without developmental coordination disorder. Research in Developmental Disabilities, 34(9), 2831-2837.

Kim, S. (2015). The mind in the making: Developmental and neurobiological origins of mentalizing. Personality Disorders: Theory, Research, and Treatment, 6(4), 356-365.

Lu, L., Petersen, F., Lacroix, L., \& Rousseau, C. (2010). Stimulating creative play in children with autism through sandplay. Arts in Psychotherapy, 37(1), 56-64.

Midgley, N., Besser, S. J., Fearon, P., Wyatt, S., Byford, S., \& Wellsted, D. (2019). The Herts and Minds study: Feasibility of a randomised controlled trial of Mentalization- Based 
Treatment versus usual care to support the wellbeing of children in foster care. BMC Psychiatry, 19, Article 215.

Muller, N., \& Midgley, N. (2015). Approaches to assessment in time-limited MentalizationBased Therapy for Children (MBT-C). Frontiers in Psychology, 6, Article 1063.

Perepletchikova, F., \& Goodman, G. (2014). Two approaches to treating preadolescent children with severe emotional and behavioral problems: Dialectical behavior therapy adapted for children and mentalization-based child therapy. Journal of Psychotherapy Integration, 24(4), 298-312.

Ramires, V. R. R., Schwan, S., \& Midgley, N. (2012). Mentalization-based therapy with maltreated children living in shelters in southern Brazil: A single case study. Psychoanalytic Psychotherapy, 26(4), 308-326.

Ritzi, R. M., Ray, D. C., \& Schumann, B. R. (2017). Intensive short-term child-centered play therapy and externalizing behaviors in children. International Journal of Play Therapy, $26(1), 33-46$.

Slade, A., Holland, M. L., Ordway, M. R., Carlson, E. A., Jeon, S., Close, N., ... \& Sadler, L. S. (2020). Minding the Baby®: Enhancing parental reflective functioning and infant attachment in an attachment-based, interdisciplinary home visiting program. Development and Psychopathology, 32(1), 123-137.

Steenbeek, H., Van der Aalsvoort, D., \& Van Geert, P. (2014). Collaborative play in young children as a complex dynamic system: Revealing gender related differences. Nonlinear Dynamics, Psychology, and Life Sciences, 18(3), 251-276.

Suchman, N. E., DeCoste, C. L., McMahon, T. J., Dalton, R., Mayes, L. C., \& Borelli, J. 
(2017). Mothering From the Inside Out: Results of a second randomized clinical trial testing a mentalization-based intervention for mothers in addiction treatment.

Development and Psychopathology, 29, 617-636.

Trawick-Smith, J., \& Dziurgot, T. (2011). 'Good-fit' teacher-child play interactions and the subsequent autonomous play of preschool children. Early Childhood Research Quarterly, 26(1), 110-123.

Wang, F., Du, Y. S., Xie, H. T., Zhou, G. Q., Li, P., Li, Z. B., ... \& Lu, Z. (2017). Effects of sandplay therapy in ADHD symptom and mother-child attachment security of children with attention deficit hyperactivity disorder. Journal of Clinical Psychiatry, 27(2), 7377. 
Declarations:

This study has passed the ethical review by department of psychology, Fudan University

Children's parents consent for publication

The datasets during and analysed during the current study available from the corresponding author on reasonable request.

The authors declare that they have no competing interests

This research did not receive any financial support

K.C. designed the research and provided supervision during the tharapy, QH.Z given the therapy, analyzed the data and finished the manuscript. All authors read and approved the final manuscript. 
Figures

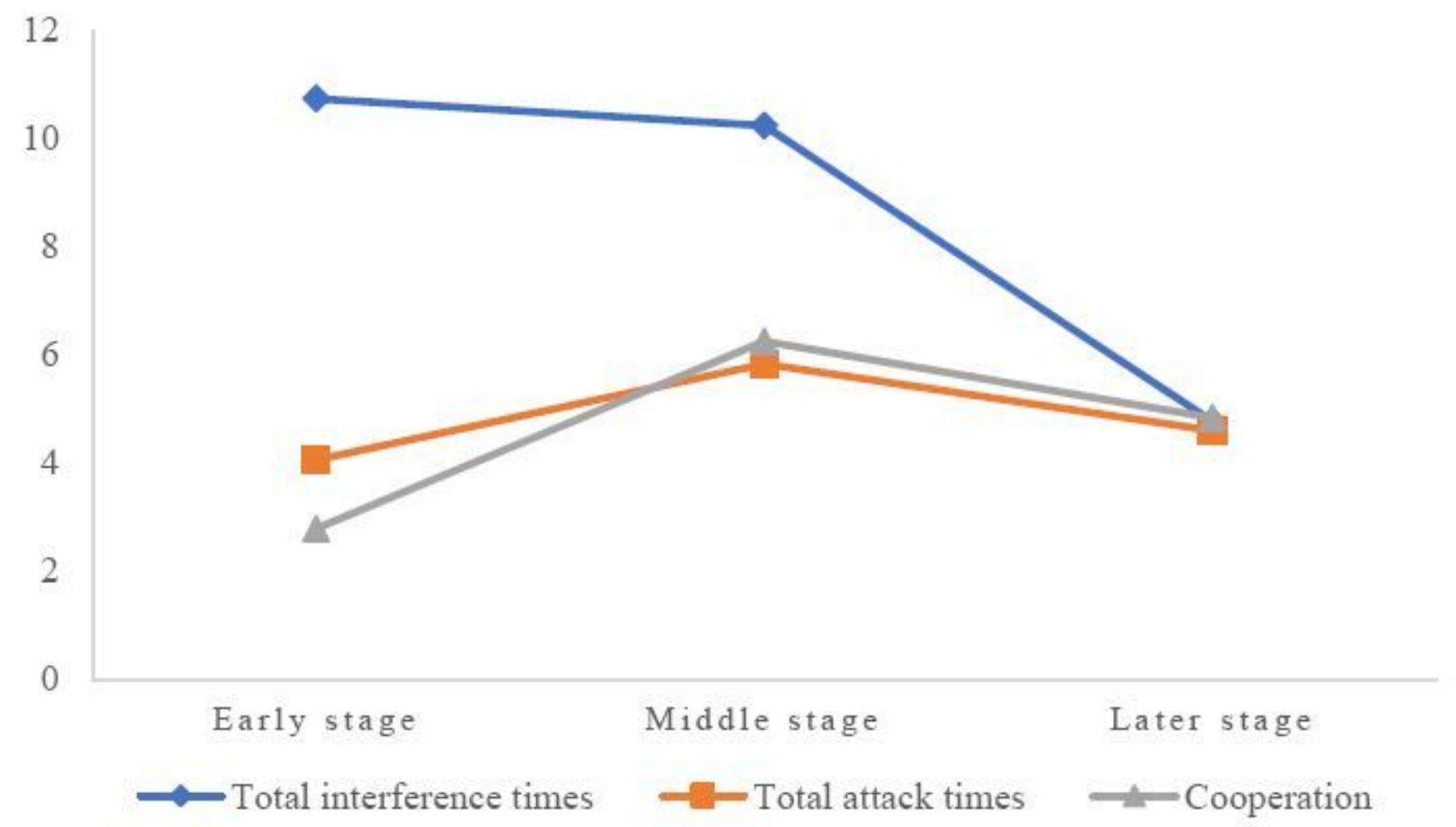

Figure 1

Average children's children's interactions 


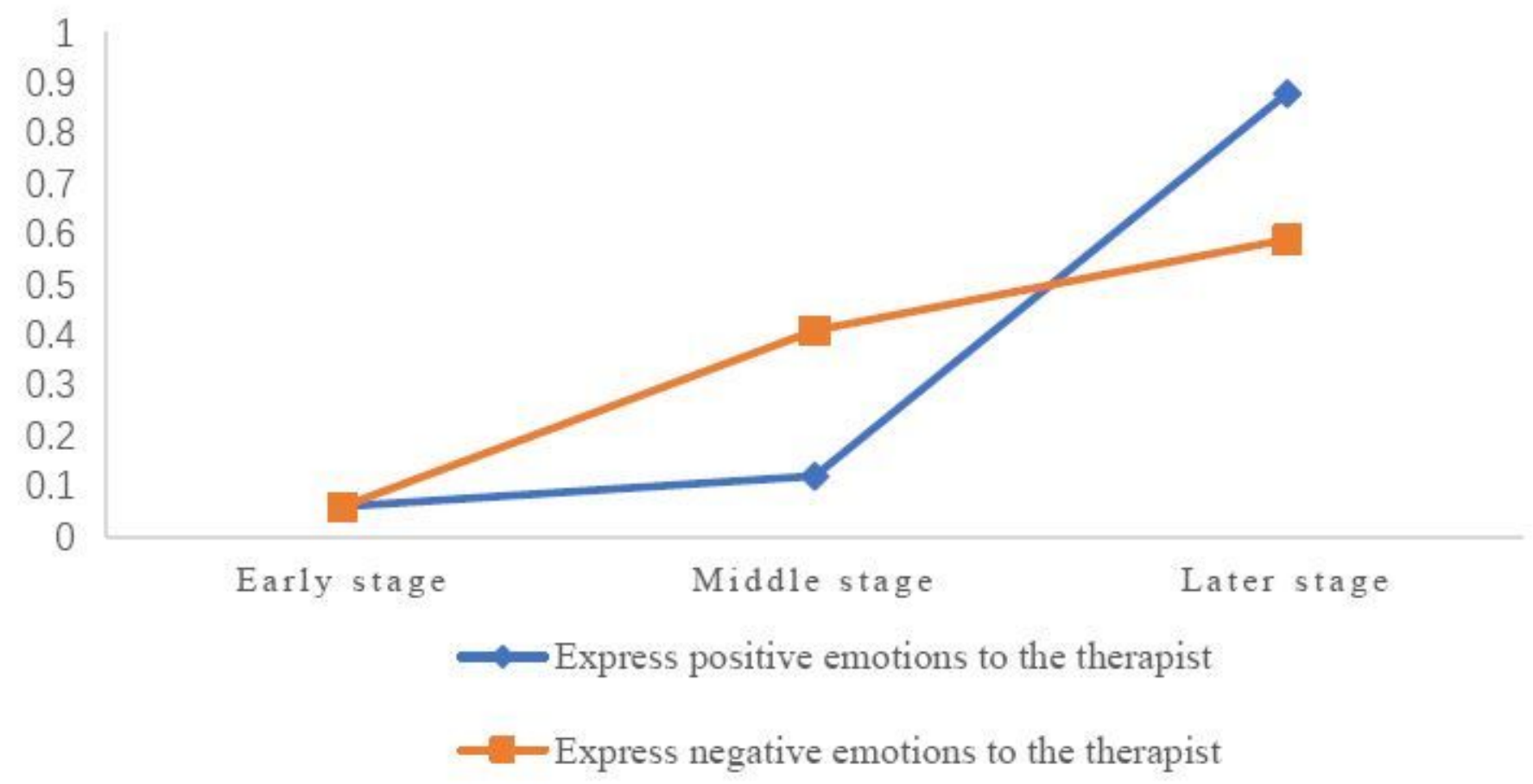

Figure 2

Average emotion expression of the children to the therapist 